\title{
PEMEROLEHAN DEMENSI PENGETAHUAN DALAM KETERAMPILAN MEMBACA TEKS BAHASA INGGRIS SISWA SEKOLAH MENEGAH ATAS
}

\author{
Muhammad Sulhan \\ Program Studi Pendidikan Bahasa Inggris, \\ Fakultas Bahasa dan Seni, Universitas Indraprasta PGRI \\ sulhanmuhammad20@gmail.com
}

\begin{abstract}
Abstrak
Anderson et al (2001) memperkenalkan cara untuk menyatakan tujuan pendidikan dalam bentuk kata kerja dan kata benda. Kata kerja umumnya mewakili proses kognitif yang diharapkan; yaitu, jenis perilaku siswa yang akan dikembangkan, sedangkan kata benda umumnya mewakili jenis pengetahuan yang diharapkan akan diperoleh oleh siswa; yaitu, konten di mana perilaku ini berproses. Penelitian deskriptif kualitatif ini bertujuan untuk mengetahui jenis-jenis pengetahuan yang diperoleh siswa dalam pengajaran pemahaman membaca teks bahasa Inggris siswa SMA. Data penelitian diambil dari kata benda yang dinyatakan dalam pertanyaan dan instruksi guru yang kemudian dianalisis dengan menggunakan daftar dimensi pengetahuan Anderson. Hasil penelitian menunjukkan bahwa siswa memperoleh $46,15 \%$ pengetahuan faktual, $38,46 \%$ pengetahuan konseptual, dan $15,38 \%$ pengetahuan prosedural.
\end{abstract}

Kata Kunci: tujuan pendidikan, jenis pengetahuan, keterampilan membaca.

\begin{abstract}
Anderson et al (2001) introduces the way to state educational objectives in the forms of a verb and a noun. The verb generally represents the intended cognitive process; that is, the kind of student's behaviour to be developed, while the noun generally represents the kinds of knowledge to be expected and acquired by students; that is, the content in which this behaviour is to operate. This descriptive qualitative research aims to find out the kinds of knowledge acquired by students in the teaching of reading comprehension to SMA students. The data of the research is taken from the noun stated in the teachers' questions and instructions which are then analyzed by using Anderson's lists of knowledge dimension. The results show that acquired 46,15\% of factual knowledge, 38,46\% of conceptual knowledge, and $15.38 \%$ of procedural knowledge.
\end{abstract}

Keywords: educational objective, kinds of knowledge, reading comprehension skill

\section{PENDAHULUAN}

Kegiatan membaca pada tingkat dasar hanyalah merupakan usaha untuk melafalkan huruf-huruf atau kata-kata sederhana. Sesuai dengan kaidah Bahasa Indonesia, huruf-huruf atau alfabet tersebut berjumlah 26, dari A sampai $\mathrm{Z}$, yang terdiri atas 5 huruf vokal dan 21 huruf konsonan. Hurufhuruf konsonan akan bisa dibaca apabila digandengkan dengan hurufhuruf vokal untuk membentuk kata. Pada tingkat dasar siswa diajarkan membaca kata atau frasa sederhana. Dengan kata lain, siswa sekolah tingkat dasar diajarkan keterampilan membaca huruf-huruf alfabet yang selanjutnya 
dirangkai satu sama lain untuk membentuk kata bermakna. Sedangkan kegiatan membaca pada tingkat dasar dilakukan secara nyaring yang menjadi keterampilan yang penting dimiliki sebagai bentuk kelancaran berbahasa (Anggraeni, 2015).

Keberhasilan membaca pada tingkat awal di atas akan menjadi modal pada praktik-praktik membaca pada tingkat lanjutan. Hal ini dikarenakan siswa pada tingkat atas akan mendapatkan materi teks bacaan yang lebih kompleks. Apabila kertampilan membaca pada tingkat dasar kurang handal, kegiatan membaca selanjutnya akan terkendala. Kondisi demikian akan berlawanan dengan kebutuhan sumber daya manusia (SDM) di masa mendatang yang sebaiknya lebih memiliki keterampilan literasi (membaca dan menulis) yang lebih dominan dibandingkan keterampilan keterampilan orasinya (menyimak dan berbicara) (Kharizmi, 2015).

Permasalahan akan timbul pada saat siswa belajar teks bahasa asing, misalnya bahasa Inggris yang diakibatkan oleh berbagai faktor diantaranya aalh adanya perbedaan kaidah kebahasaan antara bahasa Indonesia dan bahasa Inggris. Tujuan utama pembelajaran keterampilan membaca Bahasa Inggris bukanlah keterampilan dalam membaca nyaring atau membaca pada tingkat dasar, tetapi lebih pada capaian pemahaman isi teks (Widiati \& Cahyono, 2006). Berdasarkan Peraturan Menteri Pendidikan dan Kebudayaan No. 22 tahun 2006, standar kompetensi yang diharapkan muncul dalam keterampilan membaca Bahasa Inggris adalah siswa kelas $\mathrm{X}$, misalnya, diharapkan mampu memahami makna teks fungsional pendek dan esei sederhana berbentuk narrative, descriptive dan news item dalam konteks kehidupan sehari-hari dan untuk mengakses ilmu pengetahuan. Siswa akan mengalami kesulitan yang diakibatkan oleh perbedaan kaidah kebahasaan, kosa kata, pelafalan, intonasi dan lain-lain. antara Bahasa Indonesia dan Bahasa Inggris.

Untuk mengatasi permasalahan di atas, dibutuhkan bantuan guru untuk mengarahkan siswa mencapai tujuan belajarnya. Meskipun sangat dianjurkan untuk menerapkan model pembelajaran yang berpusat pada siswa (studentcentered learning), guru tidak seharusnya melepaskan siswa berkreasi tanpa arahan. Hal ini perlu dilakukan karena banyaknya siswa yang masih pasif atau merasa malu atau kurang percaya diri untuk mengemukakan pendapatnya (Antika, 2014). Pada kelas-kelas mata pelajaran Bahasa Inggris, khususnya pada pembahasan wacana atau teks, guru perlu mencari metode atau teknik pembelajaran yang relevan agar siswa mampu memahami makna yang terkandung dalam isi bacaan yang tersedia pada buku ajar. Agar siswa mendapatkan pengetahuan dari teks bahasa Inggris yang dibacanya, guru tetap menjadi motivator dan fasilitator yang diharapkan mampu mengarahkan siswa melewati tahapantahapan pemahaman isi bacaan. Dengan demikian, akan terbentuk sinergi atau kerja sama yang baik antara siswa dan guru dalam usahanya mencapai tujuan belajar mengajar di kelas.

Ditinjau dari perspektif guru, tujuan dan pengajaran adalah dua kata yang saling berhubungan satu sama lain. Tujuan pengajaran merupakan target capaian yang diinginkan oleh guru yang dinyatakan dalam bentuk formulasi eksplisit tentang harapan perubahan yang terbentuk pada siswa melalui proses pendidikan. Dari formulasi yang telah disusun dalam tujuan pengajaran kemudian dilakukan 
tindakan yang disengaja dan beralasan (Anderson et al., 2001: 3). Mengajar yang disengaja dan beralasan memiliki beberapa tujuan untuk memfasilitasi pembelajaran karena apa yang diajarkan akan dinilai layak. Dalam lebih banyak penjelasan, aspek pengajaran yang disengaja berkaitan dengan bagaimana guru membantu siswa mencapai tujuan yang telah dinyatakan (Mahirah B, 2017). Aspek pengajaran yang beralasan berkaitan dengan tujuan apa yang dipilih oleh guru untuk siswa mereka.

Untuk mengukur apakah guru telah berhasil 'mengantarkan' siswa mencapai tujuan untuk mendapatkan pengetahuan (knowledge), perlu dilakukan analisis mendalam melalui pengamatan proses belajar mengajar di kelas. Penelitian ini dilakukan untuk menentukan jenis atau demensi pengetahuan (knowledge dimension) yang diperoleh siswa pada mata pelajaran Bahasa Inggris khususnya sub pokok bahasan membaca (reading). Hasil penelitian sebelumnya menunjukkan bahwa guru kurang memberikan kesempatan kepada siswa untuk mengembangkan proses berfikir kreatif pada saat belajar membaca teks bahasa Inggris di kelas. Dengan kata lain, guru lebih dominan memberikan instruksi-instruksi dasar sehingga siswa hanya mampu mencapai proses berpikir pada tingkatan dasar, yaitu mengingat (remembering) dan pemahaman (understanding) (Sulhan, 2015). Pada kondisi demikian perlu dilakukan penelitian lanjutan tentang jenis pengetahuan yang diperoleh oleh siswa pada saat berada pada tingkatan berpikir rendah (Lower Order Thinking Skill). Namun, tidak menutup kemungkinan bahwa guru telah menyadari bahwa siswa perlu dikawal untuk mendapatkan pengetahuan yang lebih tinggi

Anderson et al memperkenalkan cara untuk menyatakan tujuan pendidikan, yaitu disusun dalam bentuk kata kerja (verb) dan kata benda (noun). Kata kerja pada umumnya dipilih untuk mewakili proses kognitif yang dituju atau jenis perilaku siswa yang akan dikembangkan, sedangkan kata benda pada umumnya mewakili jenis pengetahuan yang diharapkan dan diperoleh oleh siswa (Anderson et al., 2001:12). Format standar tujuan pembelajaran disusun untuk membantu para guru mengklarifikasi harapan mereka sehingga siswa mencapai tujuan pembelajarannya. Sebagai contoh format standar disusun dalam sebuah pernyataan: The students will be able to, or learn to, verb noun". Pernyataan ini menjelaskan tentang tujuan pengajaran guru dalam melatih siswa untuk melakukan aktivitas berupa instruksiinstruksi menggunakan kata kerja (verb) agar siswa mendapatkan pengetahuan dengan menggunakan kata benda ( $\underline{\text { noun }})$ tertentu (Anderson et al., 2001). Dengan pernyataan ini akan bisa ditentukan keterkaitan antara kategori proses kognitif dan kategori pengetahuan yang diharapkan akan diperoleh oleh siswa dalam kegiatan pembelajarn.

Keterkaitan antara kategori proses kognitif dan kategori pengetahuan dapat dilihat pada Tabel 1 . Tabel ini berusaha memadukan antara dimensi proses kognitif (cognitive process demension) yaitu remember, understand, apply, analyse, evaluate dan create dengan demensi pengetahuan (knowledge demension), yaitu factual knowledge, conceptual knowledge, procedural knowledge dan metacognitive knowledge. Dari tabel ini bisa difahami bahwa remember dan factual knowledge merupakan tingkatan proses pikir dan jenis pengetahuan yang paling rendah. Sebaliknya create dan metacognitive knowledge menjadi tingkat proses pikir dan jenis 
pengetahuan yang paling tinggi. Dengan memadukannya guru dapat dengan mudah menentukan proses kognitif yang akan dikembangkan dan jenis pengetahuan yang diperoleh oleh siswa. Tabel ini juga berguna untuk mengukur bagaimana sebuah instruksi benar-benar berdampak pada tingkat pembelajaran. Oleh karena itu, guru dapat menggunakannya untuk melacak tingkat kognisi yang mereka butuhkan dari siswa dan menentukan dimensi pengetahuan yang ingin dicapai yang telah dirumuskan dalam tujuan pendidikan.

Table 1 The Taxonomy Table (Anderson et al, 2001)

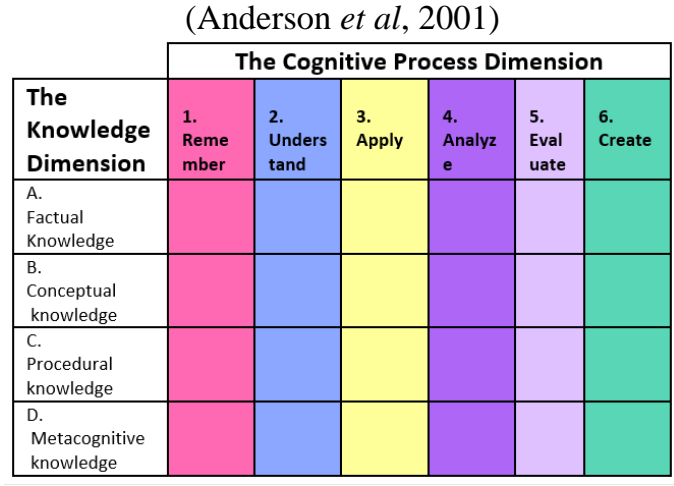

Sebagaimana diungkapkan di atas bahwa selain unsur proses kognisi yang cara merumuskannya diwakili dengan menggunakan kata kerja (verb), demensi pengetahuan merupakan unsur lain yang dapat dinyatakan dalam rumusan tujuan pembelajaran yaitu dengan menggunakan kata benda (noun). Dimensi pengetahuan dibagi menjadi empat kategori yang disusun dari konkret ke abstrak: a. Faktual, b. Konseptual, c. Prosedural dan d. Metakognitif (Anderson et al, 2001). Berikut adalah penjelasan masingmasing demensi.

a. Pengetahuan Faktual adalah unsurunsur dasar yang harus diketahui siswa untuk berkenalan dengan disiplin atau memecahkan masalah di dalamnya. Ini termasuk pengetahuan terminologi (misalnya, kosakata teknis, simbol musik, dan lain-lain), pengetahuan tentang detail dan elemen tertentu (misalnya sumber daya alam utama, sumber informasi yang andal, dan lain-lain).

b. Pengetahuan Konseptual adalah keterkaitan antara unsur-unsur dasar dalam struktur yang lebih besar yang memungkinkan unsur-unsur berfungsi bersama. Ini termasuk pengetahuan tentang klasifikasi dan kategori (misalnya, periode waktu geologis, bentuk kepemilikan bisnis), pengetahuan tentang prinsip dan generalisasi (misalnya, teorema pythagoras, hukum persediaan dan demans), pengetahuan tentang teori, model, dan struktur (misalnya, teori evolusi, struktur kongres).

c. Pengetahuan prosedural adalah pengetahuan tentang bagaimana melakukan sesuatu, metode penelitian dan kriteria untuk menggunakan keterampilan, algoritma, teknik, dan metode. Ini termasuk pengetahuan keterampilan dan algoritma khusus subjek (misalnya, keterampilan yang digunakan dalam melukis dengan warna air, algoritma pembagian nomor), pengetahuan teknik dan metode khusus subjek (misalnya, teknik wawancara, metode ilmiah), pengetahuan tentang kriteria untuk menentukan kapan harus menggunakan prosedur yang tepat (misalnya, kriteria yang digunakan untuk menentukan kapan harus menerapkan prosedur yang melibatkan hukum Newton kedua, kriteria yang digunakan untuk menilai kelayakan menggunakan metode tertentu untuk memperkirakan biaya bisnis).

d. Pengetahuan Metakognitif adalah pengetahuan kognisi secara umum serta kesadaran dan pengetahuan 
kognisi seseorang. Ini termasuk pengetahuan strategis (misalnya, pengetahuan tentang menguraikan sebagai sarana untuk menangkap struktur unit materi pelajaran dalam pengetahuan buku pelajaran tentang penggunaan heuristik), pengetahuan tentang tugas-tugas kognitif (misalnya, termasuk pengetahuan kontekstual dan kondisional), pengetahuan tentang jenis tes yang dikelola guru tertentu, pengetahuan tentang tuntutan kognitif dari tugas yang berbeda.

Sementara itu, tujuan pengajaran membaca bahasa Inggris telah diatur untuk memberikan ruang kelas yang komunikatif. Guru bahasa Inggris disarankan merancang rencana pembelajaran mengajar membaca untuk siswa SMA Kelas X berdasarkan Standar Kompetensi (SK) dan Kompetensi Dasar (KD) sesuai dengan silabus yang telah ditetapkan.

Terlepas dari indikator yang telah dirumuskan pada SK dan KD di atas, pada umumnya tujuan membaca adalah dalam rangka untuk mengetahui isi teks; yaitu untuk menangkap pemikiran dan ide penulis. Ketika seseorang telah selesai membaca sebuah teks, diharapkan orang tersebut telah memahaminya. Seseorang tidak akan mampu mencapai tingkat pemahaman tanpa usaha keras. Dalam hal ini, terjadi proses interaksi pembaca dengan isi teks untuk mengumpulkan makna.

\section{METODE PENELITIAN}

Penelitian ini menggunakan pendekatan kualitatif dalam bentuk analisis narasi data tetapi juga mencakup aspek kuantitatif berupa angka jumlah frekwensi perolehan data dan persentasenya. Peneliti mengunjungi dan mencatat kegiatan kelas ketika Guru 1 (G1) dan Guru 2 (G2) yang merupakan guru bahasa
Inggris SMA yang sedang mengajar sub pokok bahasan pemahaman bacaan (reading comprehension). Kegiatan belajar mengajar direkam dan dianalisis bentuk-bentuk pertanyaan dari guru untuk ditentukan jenis pengetahuan yang diperoleh oleh siswa. Langkah triangulasi dilakukan dengan melakukan observasi langsung ke kelas, wawancara dengan guru yang diamati dan dengan beberapa siswa dari kelas yang dijadikan sebagai tempat penelitian.

Ada 40 (empat puluh) pertanyaan atau isntruksi utama yang dipilih dari 8 (delapan) kali kunjungan yang akan dianalisis. Dari setiap kunjungan diambil lima pertanyaan utama. Pada setiap pertanyaan biasanya mengandung kata kerja dan kata benda yang digunakan oleh guru untuk mengarahkan siswa pada tingkat pemahaman isi bacaan. Kata kerja pada pertanyaan menunjukkan proses kognitif yang dikembangkan oleh guru dan kata benda yang muncul setelah kata kerja menunjukkan pengetahuan yang akan diterima oleh siswa. Tabel Taksonomi (Tabel 1) digunakan untuk memetakan jenis kata kerja dan kata benda pada tiap pertanyaan atau instruksi utama.

\section{HASIL DAN PEMBAHASAN}

Penelitian ini bertujuan untuk menentukan jenis pengetahuan yang diperoleh siswa dalam mata pelajaran bahasa Inggris pada sub pokok bahasan pemahaman membaca (reading comprehension). Data yang dianalisis adalah berupa kata benda yang terdapat pada pertanyaan atau instruksi guru yang diajukan kepada siswa untuk mencapai tingkat pemahaman teks bahasa Inggris. Tabel 2 menunjukkan bahwa siswa mendapatkan pengetahuan Faktual sebanyak 46,15\%, pengetahuan Konseptual sebanyak 38,46\% dan pengetahuan Prosedural sebanyak 
15.38\%. Hasil analisis juga menginformasikan bahwa guru tidak berhasil mengantarkan siswa untujk mendapatkan jenis pengetahuan Metakognitif.

Table 2 Jenis pengetahuan yang diperoleh oleh siswa

\begin{tabular}{|l|l|r|r|c|c|}
\hline No & $\begin{array}{l}\text { Jenis } \\
\text { Pengetahuan }\end{array}$ & $\begin{array}{r}\text { Tercap } \\
\text { ai }\end{array}$ & $\begin{array}{c}\text { Tidak } \\
\text { tercap } \\
\text { ai }\end{array}$ & $\begin{array}{c}\text { Frekwe } \\
\text { nsi }\end{array}$ & $\%$ \\
\hline 1 & Faktual & $\checkmark$ & & 24 & $46.15 \%$ \\
\hline 2 & Konseptual & $\checkmark$ & & 20 & $38.46 \%$ \\
\hline 3 & Prosedural & $\checkmark$ & & 8 & $15.38 \%$ \\
\hline 4 & Metakognitif & & $\checkmark$ & & $0 \%$ \\
\hline \multicolumn{2}{l|}{} & & & & \\
\hline
\end{tabular}

Berikut adalah pembahasan masing-masing perolehan jenis pengetahuan yang diperoleh siswa pada saat guru dan murid membahas teks narasi, teks deskriptif, teks prosedur dan teks recount.

\section{Pengetahuan Faktual}

Tabel 2 menunjukkan bahwa dari total 52 temuan, terdapat 24 atau $46.15 \%$ jenis pengetahuan Faktual yang diperoleh oleh siswa yang dianalisis dari kata benda yang terkandung dalam pertanyaan dan/atau instruksi guru. Salah satu contoh pertanyaan yang mengandung kata benda yang mewakili jenis pengetahuan dasar Faktual adalah yang disampaikan oleh G1 pada saat membahas teks Prosedur: "What materials are needed to make a cheese omelette?" Secara sederhana kata materials merujuk pada kata benda atau fakta. Dengan pertanyaan ini G1 bertujuan agar siswa mendapatkan pengetahuan jenis Faktual. Berikut ini adalah contohcontoh pertanyaan atau instruksi lain di mana G1 dan G2 menghendaki siswa mendapatkan pengetahuan Faktual.
1. Mention the title of the story from the following pictures!

2. Please read the first paragraph loudly!

3. Pronounce these words correctly!

4. The synonym of dusted (paragraph 3) is ...

5. Mention the name of the place, person, thing of the next pictures!

6. How is Sassy's fur?

7. Why is it called a clever pet?

Pertanyaan dan instruksi di atas mengandung kata benda (kata atau frasa yang digarisbawahi) yang diajukan kepada siswa terkait dengan disiplin istilah atau memerintahkan siswa untuk memecahkan masalah. Kata-kata benda tersebut bisa digolongkan pada kelompok pengetahuan terminologi, pengetahuan tentang detail dan elemen sebagai ciri jenis pengetahuan Faktual.

2. Pengetahuan Konseptual

Tabel 2 menunjukkan bahwa dari total 52 temuan, terdapat 20 atau $38.46 \%$ jenis pengetahuan Konseptual yang diperoleh oleh siswa yang dianalisis dari kata benda yang terkandung dalam pertanyaan dan/atau instruksi guru. Salah satu contoh pertanyaan yang mengandung kata benda yang mewakili jenis pengetahuan Konseptual adalah yang disampaikan oleh Guru 2 pada saat membahas teks Recount: "Identify the action verbs in the text and state the kinds of tense which involved!" Instruksi G2 ini diawali dengan sebuah kata perintah "indentify" yang disambungkan dengan kata benda dalam bentuk frasa the action verbs. Dengan instruksi ini, G2 menghendaki siswa untuk menyebutkan pola umum jenis kata kerja aksi yang berhubungan dengan pengetahuan tentang konsep 
klasifikasi. Dengan kata lain, G2 telah mengarahkan siswa untuk mendapatkan pengetahuan Konseptual.

Berikut ini adalah contohcontoh pertanyaan atau instruksi lain di mana G1 dan G2 menghendaki siswa mendapatkan pengetahuan Konseptual.

1. What type of the text is it?

2. Which paragraph is the orientation?

3. Please find the words from the text which are classified as noun, adjective, adverb, etc!

4. What is the generic structure of descriptive text?

5. What is the goal of the text?

Pertanyaan dan instruksi di atas mengandung kata benda (kata atau frasa yang digarisbawahi) yang mengandung pengetahuan tentang klasifikasi atau kategori, pengetahuan tentang prinsip atau generalisasi dan pengetahuan tentang teori. Dengan kata lain, G2 sedang mengarahkan siswa untuk mendapatkan pengetahuan Konseptual.

3. Pengetahuan Prosedural

Tabel 2 menunjukkan bahwa dari total 52 temuan, terdapat 8 atau $15.38 \%$ jenis pengetahuan Prosedural yang diperoleh oleh siswa yang dianalisis dari kata benda yang terkandung dalam pertanyaan dan/atau instruksi guru. Salah satu contoh pertanyaan yang mengandung kata benda yang mewakili jenis pengetahuan Prosedural adalah yang disampaikan oleh G1 dan G2 pada saat membahas teks naratif: "Please mention the structure of narrative text?" Dengan instruksi ini G1 menghendaki siswa untuk menyebutkan susunan (the structure) paragraf narasi. Kata benda the structure ini bisa dikelompokkan pada pengetahuan Prosedural di mana siswa diharapkan mampu menyebutkan urutan penyusunan paragraf naratif secara tertib.

Berikut ini adalah contohcontoh pertanyaan atau instruksi lain di mana G1 dan G2 menghendaki siswa mendapatkan pengetahuan Prosedural.

1. How many steps are there?

2. What do you do after heating the oil in a frying pan?

3. What is the last step in making a cheese omelet?

Pertanyaan dan instruksi di atas mengandung kata benda (kata atau frasa yang digarisbawahi) yang mengandung pengetahuan prosedural yaitu tentang bagaimana melakukan sesuatu yang melibatkan keterampilan, teknik, dan metode. Dengan kata lain, G1 sedang mengarahkan siswa untuk mendapatkan pengetahuan Prosedural.

\section{SIMPULAN}

1. Pada penelitian ini diepoleh hasil bahwa guru telah mengarahkan siswa untuk mendapatkan 3 jenis pengetahuan, yaitu pengetahuan Faktual, pengetahuan Konseptual dan pengetahuan Prosedural.

2. Pada penelitian ini tidak diperoleh data yang menunjukkan bahwa siswa memperoleh jenis pengetahuan Metakognitif. Kenyataan ini menunjukkan bahwa guru tidak memberikan kesempatan kepada siswa untuk memiliki kemampuan berfikir kritis (Sulhan, 2015) sehingga kesempatan untuk mendapatkan jenis pengetahuan tingkat tinggi juga tidak tercapai. 


\section{DAFTAR PUSTAKA}

Anderson, L. W., et al .2001. A taxonomy for learning, teaching, and assessing. New York: Longman.

Anggraeni, K. (2015). Efektivitas Metode Steinberg Dengan Media Big Book, 83-94. https://doi.org/10.1016/S0169555X(02)00319-7

Antika, R. R. (2014). Proses Pembelajaran Berbasis Student Centered Learning (Studi Deskriptif di Sekolah Menengah Pertama Islam Baitul 'Izzah, Nganjuk ). BioKultur, 3(1), 251263.

B, M. (2017). Evaluasi Belajar Peserta Didik (siswa). Jurnal Idaarah, 1(2), 257-267.

Kharizmi, M. (2015). Feldpostbrief des Staatlichen Gymnasiums DresdenNeustadt. Jupendas: Jurnal Pendidikan Dasar, 2(2), 11-21. Retrieved from https://www.neliti.com/id/publicati ons/71420/kesulitan-siswasekolah-dasar-dalammeningkatkan-kemampuan-literasi

Santosa, D. T., \& Us, T. (2016). Faktorfaktor Penyebab Rendahnya Motivasi Belajar dan Solusi Penanganan pada Siswa Kelas XI Jurusan Teknik Sepeda Motor. Jurnal Pendidikan Teknik Otomotif, 14(2), 14-21. Retrieved from

http://journal.student.uny.ac.id/ojs/ index.php/otomotifs1/article/viewFile/2896/2504

Sulhan, M. (2015) Mapping Out the Teaching Of Reading Comprehension To Senior High School Students: A Bloom's Taxonomy Perspective. Journal Developing English And Language Teaching Vol 05/03

Widiati, U., \& Cahyono, B. Y. (2006). The Teaching of EFL Speaking In the Indonesian Context: The State of the Art. Bahasa Dan Seni, 34(2), 269-292. https://doi.org/10.15639/TEFLINJ OURNAL.V19I1/1-17 